\title{
Knowledge and Attitude of Human Papillomavirus Vaccination and associated Factors Among Adolescent School Girls in Ambo Town, Oromia Region, Ethiopia, 2021
}

\author{
Mulugeta W/mariam Beyen \\ Ambo University College of Medicine and Public Health \\ Gizachew Abdisa Bulto \\ Ambo University \\ Eshetu Ejeta Chaka \\ Ambo University \\ Ephrem Yohannes Roga ( $\nabla$ efremjohn27@gmail.com ) \\ Ambo University \\ Bikila Terefa Debelo \\ Ambo University \\ Maru Mosisa Erena \\ Ambo University \\ Tefera Likasa Tefu \\ Ambo University
}

\section{Research Article}

Keywords: Human papilloma virus (HPV) vaccine, Adolescent school Girls, Ambo town

Posted Date: December 30th, 2021

DOI: https://doi.org/10.21203/rs.3.rs-1181305/v1

License: (-) (1) This work is licensed under a Creative Commons Attribution 4.0 International License. Read Full License 


\section{Abstract \\ Background}

Large-scale HPV vaccination offers a revolutionary new tool, especially in low- and middle-income countries, where $86 \%$ of cervical cancer cases and $88 \%$ of related deaths occur. There is little research done on knowledge and attitudes towards HPV vaccine in Ethiopia. Therefore, this study attempts to assess knowledge and attitudes regarding HPV vaccination and related factors among adolescent girls in Ambo town, Oromia, Ethiopia, in 2021.

\section{Methods}

A cross sectional study was conducted from May 01 to 30,2021, at selected schools of Ambo town among 422 adolescent Girls. The collected data were coded, entered, and cleaned by using Epi-Info 7.2.3 and exported to Statistical package for social science version 25 for analysis. Descriptive statistics were used to compute summary statistics and proportion. Variables at a cut off value $(0.25)$ on bivariate and $(0.05)$ on multivariate logistic-regression were used to identify predictors that were associated to knowledge and attitude of HPV vaccine among Adolescent Girls

\section{Result}

Current study revealed that $24.9 \%$ (103) and $55.6 \%$ (230) of respondents had good knowledge and favorable attitude respectively. The factors like educational level (AOR=2.011 95\% $\mathrm{Cl} ;(1.239,3.265))$, having health workers as a source of information $(\mathrm{AOR}=2.132,95 \% \mathrm{Cl} ;(1.304,3.486))$, and respondents who have heard about $\mathrm{HPV}$ vaccine at school $(\mathrm{AOR}=1.66,95 \% \mathrm{Cl}(1.02,2.71))$ were significantly associated with respondent's knowledge of HPV vaccine. Moreover, perceived severity of the diseases $(A O R=2.894,95 \% \mathrm{Cl} ;(1.607,5.21))$, and perceived benefit of the vaccine (AOR=4.263 95\% Cl; $(2.431,7.475))$ were the two factors significantly associated with attitude of the respondents about HPV vaccine.

\section{Conclusion}

There was poor knowledge and unfavorable attitude of HPV vaccination among the school Adolescents of the study area. Several seemingly major deterrents of knowledge and attitude of the HPV vaccination were identified. Therefore, awareness creation and behavioral change education is mandatory.

\section{Language Plain Summary}

Human Papilloma Virus vaccination is the research priority part in Africa where most of the women seek the treatment for the cervical cancer caused by this virus at the late stage of the disease. Therefore, this study attempts to assess knowledge and attitudes regarding Human Papilloma Virus vaccination and related factors among adolescent girls in Ambo town, Ethiopia. A study was conducted from May 01 to 30, 2021, at selected schools of Ambo town among selected adolescent Girls. From 16 primary schools and 5 high schools in the 
town of Ambo, 6 primary schools and 3 high schools were selected by lottery method. Study participants were selected from each school by simple random sampling method. A self-administered questionnaire was used to collect the data. This study revealed that $24.9 \%$ and $55.6 \%$ of respondents had overall good knowledge and favorable attitude towards Human Papilloma Virus vaccine respectively. Educational level, source of information from health workers and respondents who have heard about Human Papilloma Virus vaccine at school were significantly associated with respondent's knowledge of Human Papilloma Virus vaccine. Moreover, perceived severity of the diseases and perceived benefit of the vaccine were significantly associated with attitude of the respondents towards Human Papilloma Virus vaccine. There was poor knowledge and relatively favorable attitude of Human Papilloma Virus vaccination among the school Adolescents of the study area. Several determinants of knowledge and attitude of the Human Papilloma Virus vaccination were identified. Therefore, awareness creation and behavioral change education is mandatory.

\section{Background}

Human papillomavirus (HPV) vaccine is a prophylactic HPV vaccine developed to prevent the most common high-risk strains and low-risk infections of human papillomavirus (1). It meets an important public health need and was an important part of strategies to fight cervical cancer. Ensuring universal access to HPV vaccination was key to reducing the global burden of cervical cancer (2).

Several years ago, before this vaccine was developed, several new cases and deaths from cervical cancer occurred around the world. More than $85 \%$ of those affected are young, uneducated women living in the world's poorest countries. Many were also mothers of young children whose survival was later cut short by the untimely death of their mothers (3). In addition, the level of affection increases when access to pre-screening and treatment is limited, patients go to the doctor when complications are at an advanced stage, and most of them do not have access to emergency program service (2).

Large-scale HPV vaccination offers a revolutionary new tool, especially in low and middle-income countries, where $86 \%$ of cervical cancer cases and $88 \%$ of related deaths occur. Thus, the advent of vaccines has enabled effective primary prevention of the catastrophic consequences of cervical cancer. Even so, its use is high in countries that have an HPV vaccination program, integrate it into vaccination programs, and engage with different advertising systems while rates are low for those who have been vaccinated against HPV (4).

In an effort to explore these reasons, many important studies have looked at adolescent knowledge and attitudes towards vaccines, in which poor knowledge and negative attitudes significantly influence vaccine uptake (5-7). On the other hand, several studies have looked at the factors that hinder HPV vaccination and the challenges that limit progress in HPV and cancer prevention. Their results also suggest that common associated factors contribute to low HPV vaccine uptake; at the community level (e.g., social group values and norms, media coverage around HPV vaccines), at the organizational level (e.g., resources allocated, providing information, consent process, immunization settings and in the provincial program HPV vaccination) $(8,9)$.

Every two minutes a woman dies from cervical cancer. This worst and fourth leading cause of death continues to affect approximately 570,000 women with approximately 311,000 deaths worldwide. Of these, over $85 \%$ of deaths occur in less developed countries $(3,9)$. In East Africa, it is estimated that cervical cancer affects 42.7 
cases per 100,000 women and causes the death of 35 per 100,000 women (3). As a result, cervical cancer is the second most common cancer among women in Ethiopia with an estimated annual death toll of $4,884(10)$.

One of these challenges is the lack of knowledge about the HPV vaccine. A study conducted in other parts of the world found that the majority of adolescents were unfamiliar with the HPV vaccine (this rate reaches $90.1 \%$ in Latvia), which is a major obstacle to receiving the HPV vaccine $(6,7)$. As with most teens, there is a misconception about the HPV vaccine, which makes it difficult to accept $(7,11)$. Even the successful implementation of a vaccination program is hampered by this key demographic factor (12). A school-based intervention study of adolescents found that vaccination readiness in the intervention group increased by 31.9 times the intervention each year to improve their knowledge (12).

On the other hand, the acceptability of the HPV vaccine is largely due to their attitudes and beliefs towards the vaccine (13). It was also shown that the reason for not vaccinating in all groups was delay and refusal was the attitude that there was no need for vaccines (14). These negative attitudes (hesitations) are not limited to those who refuse vaccination, but also to those who encourage others to refuse vaccination. So why, many healthcare professionals have reported increasing challenges in building trusting relationships with parents and adolescents of the recommended age $(15,16)$.

The influence of poor knowledge and negative attitudes is not limited to adolescents; it extends from the influence of those who play their important role. About $87.3 \%$ of adolescents do not have parental and family support to immunize due to a lack of knowledge and unfavorable attitudes (13). Over the past few years, the CDC has collected data that has found that lack of vaccine knowledge was the main reason parents chose not to give their children the HPV vaccine (17). Parents often delay the decision to get the HPV vaccine because they think their child is at low risk for HPV infection $(13,17)$. Even their negative perceptions and attitudes as well as a lack of knowledge about vaccination can gradually reduce HPV vaccination rates (18). Therefore, this study aimed to present detailed evidence and fill the gap by providing information regarding level of knowledge and attitude of human papilloma virus vaccination and its associated factors among Adolescent Girls at selected schools in the study area.

\section{Methods}

\section{Study design, period and setting}

The study was conducted in the town of Ambo, west Shewa area of Oromia Regional State in Ethiopia from May 1 to 30, 2021. The town of Ambo is located approximately $114 \mathrm{~km}$ away, west of Addis Ababa, the capital of Ethiopia. The city has six (6) administrative units (small administrative units) with an estimated total population of $2,381,079$, of which $1,214,350$ are women. It has sixteen (16) primary schools, including nine (9) public schools and seven (7) private schools, and a total of five (5) secondary schools, including four (4) public schools and one (1) private school. The number of adolescent girls enrolled by school among all public and private schools was 10,091. Based on a report from the Ambo City Health Unit, 2020, the first round of HPV vaccination began with a campaign in all primary schools for 14 -year-old girls only since 2018 . A crosssectional study plan was carried out to conduct the study on 1418-year-old adolescent girls from randomly selected schools in the city of Ambo during the study period. 


\section{Sample size determination and Sampling Procedure}

\section{Sample size determination}

The sample size was determined using the single population ratio formula by estimating knowledge and attitudes about HPV (P) at 50\%, as no studies have been conducted in this area. To get the largest sample size, $Z=$ the $95 \%$ confidence normal distribution value is $Z$ a $/ 2=1.96$, and the error $(d)=5 \%$ and the alpha value is 0,05 . Therefore, assuming $10 \%$ as the non-response rate, the final total sample size was 422 study participants. Of the sixteen (16) primary schools and five (5) high schools in the town of Ambo, six (6) primary schools and three (3) high schools were drawn by lot. For each school selected, the sample size was distributed in proportion to the number of adolescent girls aged 14-18 in each school. Study participants were selected from each school by simple random lottery sampling.

\section{Operational Definition}

Adolescence - The age between 10 to 19 years (2) .

Knowledgeable- There were three subsections of knowledge specific to cervical cancer, knowledge of HPV infection and knowledge of the HPV vaccine with a maximum possible score of 32. The three sections were; knowledge of cervical cancer, Cervical Cancer Knowledge of HPV Infection and Knowledge of HPV Vaccine will have 12, 13 and 7 knowledge related questions respectively. For knowledge of HPV vaccination, the knowledge scores was ranged from 0-7 depending on whether the respondents answered correctly or incorrectly, assigning 1 point for each correct answer and 0 for each incorrect answer. The total score was calculated and the average and below average can be considered ignorant (poor knowledge) while an above average score is displayed as Knowledgeable (good knowledge). The same approach was used for knowledge of cervical cancer, knowledge of sections on HPV infection and global knowledge (16).

Attitude A total of seven items with a five-point scale were developed to measure attitudes towards the HPV vaccine. It was awarded 5 points for "totally agree" reduced to 1 point for "totally disagree". Therefore, all questions were coded in binary and coded as " 1 " for "agree" and "0" for the response "disagree". Then, attitude scores were calculated for each participant, ranging from 0 to 7 . Finally, a composite attitude variable was generated from the score using the mean as the cutoff score when checking for normality of the score. Participants with above-average scores was classified as having "favorable attitudes", while those with average and below-average scores was classified as having "unfavorable attitudes" (19).

Perception- A total of 13 items were constructed for all sections of perception. Susceptibility of diseases, Severity of diseases, Benefits of HPV vaccine preventable, Barriers to HPV vaccination; each category has three items unless barriers to HPV vaccination which has 4 items. The available responses were noted on a licking scale; 1 = strongly disagree; 2 = Disagree; $3=$ neither agree nor disagree; $4=$ agree; $5=$ totally agree. Therefore, all questions were coded in binary and coded as " 1 " for "agree" and "0" for the response "disagree". Then, each perception score was calculated for each section using the mean as the cutoff score. For example, for participants whose severity is perceived with above-average scores were classified as having "highly perceived disease severity," while those with average and below-average scores were classified as having "low perceived severity of the disease". Finally, a composite perception was generated from all the variables using the mean 
score as the cutoff score. Participants with above-average scores were classified as having "good perception"

while those with average and lower than average scores were classified as having "poor perception". Therefore, a score below the average indicates a stronger belief in refusing vaccination and was labeled as "Poor Perception" while a score above the average was considered to be "Good Perception"(19).

\section{Data Collection Tool and Procedure}

The questionnaire was prepared in English language that was translated into Afan Oromo and then translated back into English to check its consistency. The questionnaires have been adapted through a review of different literature and similar previous studies. An eight-part questionnaire was developed to assess sociodemographic characteristics, knowledge about cervical cancer, HPV infection and vaccination, awareness and attitudes towards HPV vaccination, presence HPV vaccination advertisements and information resources. A self-administered Afan Oromo version questionnaire was used to collect the data. To administer the structured questionnaire, eight (8) teachers as data coordinators and eight (8) experienced data investigator nurses were appropriately selected and 3 master's degrees in health-related supervisory sciences were recruited and trained during a day on the objectives, the relevance of the study, confidentiality, information, respondent rights, informed consent and interview techniques.

\section{Data Quality Assurance}

To maintain data quality, interviewers and supervisors were trained in data collection procedures. Prior to the actual data collection, the questionnaire (instrument) was pre-tested for simplicity, fluidity, consistency, validity and reliability on $5 \%$ of samples in schools that were not covered there by adjustment or modification which may have been considered / at the time of the offer and minor corrections to some of the issues which were included. Principal investigators and supervisors carried out on-site checks and reviews of all completed questionnaires to ensure the completeness and consistency of the information collected. The investigators were supervised by three supervisors. The principal investigator performed the data entry to maintain the accuracy of the data.

\section{Data processing and analysis}

After data collection, each questionnaire was checked for completeness, and entered in to Epinfo version7.2.2.6. Then data were exported to SPSS version 25 for cleaning, editing and analysis. The data were checked for missed values and outliers. Descriptive analysis (like frequencies, tables, percentages, means, and standard deviation) was done to describe the required variable. Then all variables having P-value of less than 0.25 were considered as candidates for multivariable logistic regression models. Multivariable logistic regression at the $95 \%$ confidence level was used to identify the predictors. A significance level of 0.05 was taken as a cutoff value for all statistical significance tests. Multi-colinearity was checked between predictors using variance inflation factor for each variable. Accordingly, two variables were removed on Multivariable logistic analyses (VIF= $9.95 \& 11.5)$. Hosmer and Lemeshow goodness of fit test was done to check model fitness Goodness of fit.

\section{Results}




\section{Social demographic characteristics of respondents}

A total of 414 respondents participated in the study with a response rate of $98.1 \%$. The majority of respondents $71.5 \%$ (296) live with their parents. More than half of the respondents, $53.4 \%(221)$ were born in Urban. Regarding the level of education of their parents about a quarter reported that the father (25.8\%) and mother $(27.1 \%)$ have a primary education. By profession, the majority of respondents were born to fathers $(47.8 \%)$ and mothers (36.2\%) who were active farmers (Table 1$)$.

\section{Respondent's level of knowledge about cervical cancer, HPV infection and HPV vaccine}

More than three-fourth of girls had heard about cervical cancer and HPV vaccine $77.3 \%$ (320) and 78.7\% (326) respectively. On the other hand, about $71.7 \%$ (297) know the method of prevention of cervical cancer. However, comparing to this $57.2 \%$ (237) hadn't heard about HPV infection. Nearly three-fourth (73.9\%) of respondents doesn't know recommended doses of HPV Vaccine. Overall, the knowledge score towards cervical cancer, HPV infection and HPV vaccine is found to be very low (11.4\%) (Table2).

\section{Level of Attitude of respondents toward HPV vaccination}

Two third $(75.4 \%)$ have the view that HPV vaccine helps to prevent HPV infection. The majority $(72.7 \%)$ of the respondents agreed that cervical cancer is a deadly disease. A large portion $(72.9 \%)$ of a respondents agreed that HPV vaccination begin to minimize cervical cancer. Similarly, $72.9 \%$ of the participants were confirmed their own believes as the vaccine could save life and improve health. Though, up-to $69.1 \%$ stated their concern as having the HPV Vaccine would possibly leads to sexually promiscuous. On the other hand, about $44.7 \%$ had parental concern about having the vaccine. More than half (55.6\%) of the respondents have favorable attitude towards HPV vaccinations (Table 3).

\section{Perception of respondents toward cervical cancer, HPV infection and HPV vaccination}

The study revealed that $54 \%$ of the respondents were found to have poor perceived susceptibility; while $40 \%$ has poor perceived severity of the diseases. However, those who have good perceived benefit of HPV vaccine were about $66.5 \%$. Specially, those who perceived getting vaccination can reduce the risk of cervical cancer were about $77 \%$.Concerns about possible side effects (66.9\%), needle phobia $(61.6 \%)$ and miss understanding about HPV vaccine (57.2\%) were the main factors stated to make less intention to the vaccine (Table 4).

\section{Existence of promotion and pre-information on HPV Vaccination}

Many participants (80\%) responded that there was no incentive to educate the community about the HPV vaccine. Even around $36.2 \%$ of service providers responded that they did not provide enough information before vaccination. About half (48.6\%) of those surveyed said that HPV vaccine promotion and health education are available in school. Most participants (68.4\%) reported that HPV vaccine promotions were available in their area.

\section{Factors associated with Knowledge of HPV vaccination}

Binary logistic regression was performed to assess the association between the dependent and independent variable. Factors that showed a P-value of $<0.25$ were included in the multivariable regression model. Multiple 
logistic regression analysis showed that, educational level of the respondent and existences of source of information were associated with knowledge of HPV vaccination. Adolescents of Secondary education level were 2 times more knowledgeable about HPV vaccination as compared to Adolescents of primary education level (AOR=2.011 95\% Cl; 1.239, 3.265). Respondents who have had Health workers as their main source of information had 2 times more awareness about HPV vaccine than those who didn't heard from health providers (AOR=2.132 95\% Cl; 1.304, 3.486). Additionally, respondents who have heard about HPV vaccine at school was 1.6 times more likely to have awareness about HPV vaccine than those who didn't heard at school (AOR=1.66, 95\% Cl(1.02, 2.71)) (Table 5).

\section{Factors associated with attitude of HPV vaccination}

Adolescents who have heard about HPV vaccine prior to vaccination had 3.4 times more favorable attitude for the vaccine than those who had never heard about it ( $\mathrm{AOR}=3.425,95 \% \mathrm{Cl} ; 1.341,8.742$ ). In addition, the odds of the students who highly perceived the severity of the diseases were 2.9 times more likely to have favorable attitude for the vaccine than those who had unfavorable attitude for the vaccine (AOR=2.894 95\% $\mathrm{Cl} ; 1.607$, 5.211). Likewise, Perceived benefit of the vaccine were 4.26 higher among Adolescents who have favorable attitude for the vaccine as compared to those who had unfavorable attitude for the vaccine (AOR=4.263,95\% $\mathrm{Cl} ; 2.431,7.475)$. On the other hand, respondents whom strongly perceived the expected barriers were $50 \%$ less likely have favorable attitude as compared to those who less likely perceived the barriers $(A O R=0.5,95 \% \mathrm{Cl}$; $0.298,0.838$ ). Concerning availability of promotion, adolescents who had available awareness creation at their schools were 1.9 times more likely have positive attitude than those respondents who have not awareness creation promotion at their schools(AOR=1.927, 95\% Cl; 1.057, 3.512) (Table 6).

\section{Discussion}

In this study, the proportion of Adolescent school girls who were knowledgeable about HPV vaccination was found to be only $24.9 \%$. This was higher than two previous studies conducted on adolescent Girls of Latvia $(9.9 \%)$ and Niger $(11.4 \%)(7,20)$. However, the results from other studies in Puducherry $(43.3 \%)$ and Uganda (47.7\%)revealed better knowledge of HPV vaccination compared to the present study $(21,22)$. The variation observed can be explained by the differences in socio-economic status, study settings, cultural norms and access to information. This may be due to greater exposure to information about the HPV vaccine after the introduction of national HPV immunization as well as numerous campaigns by both public and private sectors.

The finding indicated that about $44.4 \%$ of Adolescents had unfavorable attitude for HPV vaccination, which is almost comparable to study conducted in Lagos, Nigeria (44.2\%) (23). In Contrast to our findings, another study from developed country (Italy) showed that there were lower rates of unfavorable attitude towards HPV vaccination $(20 \%)(24)$. The difference might be explained due to different in socio-economic status, educational level and low coverage of focused educational campaigns (low access of information) to target group.

Beyond assessing the prevalence rate the study also pointed out factors that were associated with Adolescent's knowledge and attitude of HPV vaccine. Having source of information from health workers and at school was found to increase Adolescent's knowledge of HPV vaccine by about two times more than their 
counter partner. This finding is in line with other similar study from USA, where Adolescents alternate school and health workers as their main source of information(25). The reason might be because school were very close to them for every information and health professionals in which they belief because they expect as health professionals were knowledgeable enough about the vaccine than any other occupation. This might be due to ethical consideration of health professionals was along with the objective of Vaccination.

This study also found that one of the factors associated with the knowledge of HPV vaccination was adolescent's level of education. The finding was consistent with a finding from similar study conducted on Mozambican and Nepali adolescents $(26,27)$. The reason might be because the students in high school have read about cancer. Cancer education is included in the Grade 10 curriculum.

In another direction the finding of the study indicated that Adolescents who have heard about HPV vaccine (who have exposure of information) before vaccination had more positive attitude for the vaccine. The result of this study was in line with study conducted in Italy(24). This may be explained by the fact that, having preinformation about the vaccine helps in recognizing the benefits of the vaccine which in turn helps to develop positive outlook for a vaccine.

Another finding of this study indicated that Adolescents those who perceived the severity of the diseases well have had more positive attitude for the vaccine. The result of this study has also in line with an evidence from the study conducted on adolescent daughters in Hong Kong and Kenya, in which perceived severity was strongly associated with positive attitude towards the HPV vaccine $(7,28)$. This may due to the reason behind the belief of diseases severity has merit because perception of illness can influence patients' emotional response to the illness and their copying behaviors, including preventive health behaviors. In addition to this, perceived benefit of the vaccine could make to have more positive attitude to the vaccine than those who do not belief in the benefit of the vaccine. The result of this study was similar with study conducted in Kenya in which perceived health benefits was strongly associated with positive attitude towards the HPV vaccine (28). This is due to recognizing the benefit of the vaccine may help to develop positive perception for a vaccine.

Another individual level factor was perceived barrier in which those who strongly perceived different barriers as it retain them from vaccination were less likely have positive belief for the vaccine. It might be explained as misunderstanding like needle phobia as well as infertility concern highly affects their views to the vaccine. This may be explained by the fact that, individual barriers to the vaccine acceptance such as fear of needle injection, side effects as well as broader socio-cultural context can negatively affect one belief toward the HPV vaccination. Other possible reason might be due to little existence of promotion and availability of information.

The current study didn't address all components of perception which might literarily well addressed by health belief model. Since the study was limited to school facilities, it was difficult to generalize to all Adolescents of similar age group living in the same district. Thus, to minimize the effect of the aforementioned limitations scholars with similar interest are recommended to conduct a community-based study.

\section{Conclusion And Recommendation}

This study revealed that the magnitude of knowledge and attitude of HPV vaccination was significantly found to be low. Adolescents of secondary education level and respondents who have had health workers as their 
main source of information were found to be statistically significant with knowledge of HPV vaccine. Adolescents who have heard about HPV vaccine prior to vaccination, students who highly perceived the severity of the diseases, perceived benefit of the vaccine, adolescents who had available awareness creation at their schools were significantly associated with favorable attitude towards HPV vaccine. On the other hand, respondents whom strongly perceived the expected barriers were less likely to have favorable attitude. Striving for the program coverage and access of HPV vaccine will not be enough unless all eligible Girls have adequate knowledge and favorable attitude for correctly and consistently taking the vaccine as per needed. Therefore, increasing awareness/knowledge and favorable attitude for HPV vaccination activities at all levels of eligible Adolescents are mandatory.

\section{Abbreviations}

HPV: Human Papilloma Virus, MCH: Maternal and Child Health, WHO: World Health Organization

\section{Declarations}

\section{Ethical approval and consent to participate}

The ethics check was obtained from the Institutional Review Board (IRB) of Ambo University, College of Medicine and Health Sciences with ID number of CMHS/R/MIDW/08/2021. Informed Oral and written informed consent was obtained from each respondent and their parents and necessarily after explaining the purpose and procedure of the study. In addition, written informed consent in a separate form of consent has been obtained separately from parents to ensure their legal preparation on behalf of their minor (for adolescents and young adults aged 18 and over). This means obtaining the written consent of the parents as a prerequisite for carrying out research on their daughter (before the start of data collection). In order to maintain the confidentiality of information provided by research subjects, the data collection process is anonymous. Participation on a voluntary basis and withdrawal from the study at any time from data collection was taken into account. No name or other identifying information was included in the questionnaire. We are confirming all the information for involving the participants was in accordance to guidelines of institutional review board of Ambo University, college of medicine and health sciences.

Consent for publication: Not applicable

Data Sharing Statement: The datasets used and/or analyzed during the current study are available from the corresponding author upon request.

Disclosure: The authors declare that they have no competing interests.

Funding: No funding was received for the current study.

Competing of interests: Not applicable

\section{Acknowledgement}


We would like to thank Ambo University, College of Medicine and Health Sciences, Department of Midwifery and Public Health for providing us with the opportunity to conduct this study. We would like to thank West Shewa zonal Health Office, study participants, data collectors and supervisors for their cooperation.

\section{Author Contributions}

MWB and GAB made substantial contributions to conception and design, EEC contributed for acquisition of data, EYR and BTD play great role of data analysis and interpretation. On top of that, TLT and MME took part in drafting the article or revising it critically for important intellectual content. All Authors agreed to submit to the current journal and gave final approval of the version to be published; and agree to be accountable for all aspects of the work.

\section{References}

1. Lee L-y, Garland SM. Human papillomavirus vaccination: the population impact. F1000Research. $2017 ; 6$.

2. Organization WH. Global strategy to accelerate the elimination of cervical cancer as a public health problem. 2020.

3. Draft W. Global Strategy Towards Eliminating Cervical Cancer as a Public Health Problem. WHO: Geneva, Switzerland.; 2019.

4. Dilley SE, Peral S, Straughn JM Jr, Scarinci IC. The challenge of HPV vaccination uptake and opportunities for solutions: lessons learned from Alabama. Preventive medicine. 2018;113:124-31.

5. Graham JE, Mishra A. Global challenges of implementing human papillomavirus vaccines. International Journal for Equity in Health. 2011;10(1):1-11.

6. Ozyer S, Uzunlar O, Ozler S, Kaymak O, Baser E, Gungor T, et al. Awareness of Turkish female adolescents and young women about HPV and their attitudes towards HPV vaccination. Asian Pacific Journal of cancer prevention. 2013;14(8):4877-81.

7. Loke AY, Kwan ML, Wong Y-T, Wong AKY. The uptake of human papillomavirus vaccination and its associated factors among adolescents: a systematic review. Journal of primary care community health. 2017;8(4):349-62.

8. Black E, Richmond R. Prevention of cervical cancer in Sub-Saharan Africa: the advantages and challenges of HPV vaccination. Vaccines. 2018;6(3):61.

9. Arbyn M, Weiderpass E, Bruni L, de Sanjosé S, Saraiya M, Ferlay J, et al. Estimates of incidence and mortality of cervical cancer in 2018: a worldwide analysis. The Lancet Global Health. 2020;8(2):e191203.

10. Asseffa NA. Cervical cancer: Ethiopia's outlook. J Gynecol Womens Health. 2017;5(2):555660.

11. Santhanes D, Yong CP, Yap YY, San Saw P, Chaiyakunapruk N, Khan TM. Factors influencing intention to obtain the HPV vaccine in South East Asian and Western Pacific regions: A systematic review and metaanalysis. Scientific reports. 2018;8(1):1-11.

12. Chang IJ, Huang R, He W, Zhang S-K, Wang S-M, Zhao F-H, et al. Effect of an educational intervention on HPV knowledge and vaccine attitudes among urban employed women and female undergraduate students in China: a cross-sectional study. BMC Public Health. 2013;13(1):1-8. 
13. Barnes KL, VanWormer JJ, Stokley S, Vickers ER, McLean HQ, Belongia EA, et al. Determinants of human papillomavirus vaccine attitudes: an interview of Wisconsin parents. BMC Public Health. 2018;18(1):746.

14. Dorell C, Yankey D, Jeyarajah J, Stokley S, Fisher A, Markowitz L, et al. Delay and refusal of human papillomavirus vaccine for girls, National Immunization Survey-Teen, 2010. Clin Pediatr. 2014;53(3):2619.

15. Yaqub O, Castle-Clarke S, Sevdalis N, Chataway J. Attitudes to vaccination: a critical review. Soc Sci Med. 2014;112:1-11.

16. Lee K-N, Chang KH-J, Cho S-S, Park S-H, Park ST. Attitudes regarding HPV vaccinations of children among mothers with adolescent daughters in Korea. J Korean Med Sci. 2017;32(1):130-4.

17. Niccolai LM, Hansen CE, Credle M, Ryan SA, Shapiro ED. Parents' views on human papillomavirus vaccination for sexually transmissible infection prevention: a qualitative study. Sex Health. 2014;11(3):274-9.

18. Perlman S, Wamai RG, Bain PA, Welty T, Welty E, Ogembo JG. Knowledge and awareness of HPV vaccine and acceptability to vaccinate in sub-Saharan Africa: a systematic review. PloS one. 2014;9(3):e90912.

19. Jaoude JA, Khair D, Hiba Dagher H, Saad P, Cherfan MA, Kaafarani, et al. Factors associated with Human Papilloma Virus (HPV) vaccine recommendation by physicians in Lebanon. Elsevier. 2018:7562-7.

20. Jalani FFM, Rani MDM, Isahak I, Aris MSM, Roslan N. Knowledge, attitude and practice of human papillomavirus (HPV) vaccination among secondary school students in rural areas of Negeri Sembilan, Malaysia. International journal of collaborative research on internal medicine public health. 2016;8(6):56.

21. Amu E, Ndugba S, Olatona F. Knowledge of cervical cancer and attitude to cervical cancer screening among women in Somolu Local Government Area, Lagos, Nigeria. Journal of Community Medicine Primary Health Care. 2019;31(1):76-85.

22. Kisaakye E, Namakula J, Kihembo C, Kisakye A, Nsubuga P, Babirye JN. Level and factors associated with uptake of human papillomavirus infection vaccine among female adolescents in Lira District, Uganda. Pan African Medical Journal. 2018;31(1).

23. Ojeleye OA, Adejumo PO. Knowledge and acceptance of HPV vaccination among Lagos students. African Journal of Midwifery Women's Health. 2019;13(2):1-8.

24. Trucchi C, Amicizia D, Tafuri S, Sticchi L, Durando P, Costantino C, et al. Assessment of knowledge, attitudes, and propensity towards HPV vaccine of young adult students in Italy. Vaccines. 2020;8(1):74.

25. Rosen BL, Shew ML, Zimet GD, Ding L, Mullins TL, Kahn JA. Human Papillomavirus vaccine sources of information and adolescents' knowledge and perceptions. Global pediatric health. 2017;4:2333794X17743405.

26. Poudel K, Sumi N. Analyzing awareness on risk factors, barriers and prevention of cervical cancer among pairs of Nepali High School students and their mothers. Int J Environ Res Public Health. 2019;16(22):4382.

27. Sopian MM, Shaaban J, Yusoff SSM, Mohamad WMZW. Knowledge, decision-making and acceptance of human papilloma virus vaccination among parents of primary school students in Kota Bharu, Kelantan, Malaysia. Asian Pacific journal of cancer prevention: APJCP. 2018;19(6):1509. 
28. Vermandere H, van Stam M-A, Naanyu V, Michielsen K, Degomme O, Oort F. Uptake of the human papillomavirus vaccine in Kenya: testing the health belief model through pathway modeling on cohort data. Globalization health. 2016;12(1):1-13.

\section{Tables}


Table 1

Socio-demographic characteristics, of Adolescent school Girls in Ambo town, Ethiopia, $2021(n=414)$

\begin{tabular}{|c|c|c|c|}
\hline \multicolumn{2}{|c|}{ Socio-demographic characteristics } & \multirow{2}{*}{$\begin{array}{l}\text { Frequency } \\
199\end{array}$} & \multirow{2}{*}{$\begin{array}{l}\text { Percent } \\
48.1 \%\end{array}$} \\
\hline Age & $14-15$ years & & \\
\hline & $16-18$ years & 215 & $51.9 \%$ \\
\hline \multirow[t]{2}{*}{ Students educational level } & Primary Education & 264 & $63.8 \%$ \\
\hline & Secondary Education & 150 & $36.2 \%$ \\
\hline \multirow[t]{5}{*}{ Fathers education level } & Unabletoreadand write & 73 & $17.6 \%$ \\
\hline & Able to read and write & 82 & $19.8 \%$ \\
\hline & Primary education & 107 & $25.9 \%$ \\
\hline & Secondary education & 62 & $15.0 \%$ \\
\hline & College Diploma and above & 90 & $21.7 \%$ \\
\hline \multirow[t]{5}{*}{ Mothers education level } & Unable toread and write & 101 & $24.3 \%$ \\
\hline & Able to read and write & 82 & $19.8 \%$ \\
\hline & Primary education & 112 & $27.1 \%$ \\
\hline & Secondary education & 76 & $18.4 \%$ \\
\hline & Collegediplomaand above & 43 & $10.4 \%$ \\
\hline \multirow[t]{5}{*}{ Fathers' Occupation' } & Merchant & 42 & $10.1 \%$ \\
\hline & Government employee & 118 & $28.6 \%$ \\
\hline & Private employee & 38 & $9.2 \%$ \\
\hline & Farmer & 198 & $47.8 \%$ \\
\hline & Other & 18 & $4.3 \%$ \\
\hline \multirow[t]{6}{*}{ Mothers' occupation } & Merchant & 58 & $14.0 \%$ \\
\hline & Government employee & 58 & $14.0 \%$ \\
\hline & Private employee & 44 & $10.6 \%$ \\
\hline & Farmer & 150 & $36.2 \%$ \\
\hline & House wife & 102 & $24.6 \%$ \\
\hline & Other & 2 & $0.5 \%$ \\
\hline \multirow[t]{2}{*}{ Place of birth } & Urban & 221 & $53.4 \%$ \\
\hline & Rural & 193 & $46.6 \%$ \\
\hline
\end{tabular}


Table 2

Cervical cancer, HPV infection and HPV vaccination related knowledge of Adolescent school Girls in Ambo town, Ethiopia, $2021(n=414)$

Variable
Knowledge towards Cervical cancer

Have you ever heard cervical cancer

Risk factor of Cervical cancer
Mode of transmission
Sign and symptom of cervical cancer

Category Frequency Percent

No

\begin{tabular}{lll} 
No & 94 & $22.7 \%$ \\
\hline Yes & 320 & $77.3 \%$ \\
\hline $\begin{array}{l}\text { Don't } \\
\text { know }\end{array}$ & 386 & $93.2 \%$ \\
\hline
\end{tabular}

$\begin{array}{lll}\text { Know } & 28 & 28.8 \%\end{array}$

Sexual transmission

No

248

$59.9 \%$

Vertical transmission

Yes

166

$40.1 \%$

Vertical transmission

No

398

$96.1 \%$

Yes

16

$3.9 \%$

Don't

325

$78.5 \%$

know

Know

89

$21.5 \%$

Over all knowledge score of Cervical cancer

\begin{tabular}{lll} 
Poor & 350 & $84.5 \%$ \\
\hline Good & 64 & $15.5 \%$
\end{tabular}

\section{Knowledge towards HPV infection}

Have you ever heard of HPV infection

Who can contract HPV infection

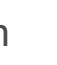

No

237

$57.2 \%$

Yes

177

$42.8 \%$

Don't

147

know

67

$16.2 \%$

Diseases caused by HPV infection

Don't

405

know

405

$97.8 \%$

Know

9

$2.2 \%$

Risk factors for HPV infection

Don't

353

know

Know

61

$14.7 \%$

MethodofpreventionofHPV infection

Don't

know

392

$94.7 \%$

Know

22

$5.3 \%$

Overallknowledgescoretowards HPV infection

Poor

377

$91.1 \%$ 


\begin{tabular}{|c|c|c|c|}
\hline Variable & Category & Frequency & Percent \\
\hline & Good & 37 & $8.9 \%$ \\
\hline \multicolumn{4}{|l|}{ Knowledge towards HPV Vaccine } \\
\hline \multirow[t]{2}{*}{ Have you ever heard about HPV vaccine before } & No & 88 & $21.3 \%$ \\
\hline & Yes & 326 & $78.7 \%$ \\
\hline \multirow[t]{2}{*}{ The benefit of HPV Vaccine } & $\begin{array}{l}\text { Don't } \\
\text { know }\end{array}$ & 146 & $35.3 \%$ \\
\hline & Know & 268 & $64.7 \%$ \\
\hline \multirow[t]{2}{*}{ Who should get the HPV vaccination } & $\begin{array}{l}\text { Don't } \\
\text { know }\end{array}$ & 291 & $70.3 \%$ \\
\hline & Know & 123 & $29.7 \%$ \\
\hline \multirow[t]{2}{*}{ Recommended doses of HPV Vaccine } & $\begin{array}{l}\text { Don't } \\
\text { know }\end{array}$ & 306 & $73.9 \%$ \\
\hline & Know & 108 & $26.1 \%$ \\
\hline \multirow[t]{2}{*}{ The ideal time HPV Vaccine best recommended } & $\begin{array}{l}\text { Don't } \\
\text { know }\end{array}$ & 331 & $80.0 \%$ \\
\hline & Know & 83 & $20.0 \%$ \\
\hline \multirow[t]{2}{*}{ Over all knowledge score of HPV vaccine } & Poor & 311 & $75.1 \%$ \\
\hline & Good & 103 & $24.9 \%$ \\
\hline \multirow{2}{*}{$\begin{array}{l}\text { Overall knowledge scoretowards Cervical cancer, HPV infection and } \\
\text { HPV vaccine }\end{array}$} & Poor & 367 & $88.6 \%$ \\
\hline & Good & 47 & $11.4 \%$ \\
\hline
\end{tabular}


Table 3

Attitude towards HPV vaccination of Adolescent school Girls in Ambo town, Ethiopia, 2021 ( $n=414)$

\begin{tabular}{|c|c|c|c|c|}
\hline \multirow[t]{3}{*}{ Variables } & \multicolumn{4}{|c|}{ Attitude toward HPV vaccine } \\
\hline & \multicolumn{2}{|c|}{ Unfavorable attitude } & \multicolumn{2}{|c|}{ Favorable attitude } \\
\hline & Frequency & Percent & Frequency & Percent \\
\hline Cervical cancer is a deadly disease & 113 & $27.3 \%$ & 301 & $72.7 \%$ \\
\hline The vaccination was began to minimize cervical cancer & 112 & $27.1 \%$ & 302 & $72.9 \%$ \\
\hline Thinks vaccination helps to prevent HPV infection & 102 & $24.6 \%$ & 312 & $75.4 \%$ \\
\hline Parental concern about having the vaccine & 185 & $44.7 \%$ & 229 & $55.3 \%$ \\
\hline HPV vaccine saves life and improve health & 112 & $27.1 \%$ & 302 & $72.9 \%$ \\
\hline Whether you recommend the vaccine to others ornot & 75 & $18.1 \%$ & 339 & $81.9 \%$ \\
\hline $\begin{array}{l}\text { Having the HPV Vaccine may become sexually } \\
\text { promiscuous }\end{array}$ & 128 & $30.9 \%$ & 286 & $69.1 \%$ \\
\hline Over all Attitude & 184 & $44.4 \%$ & 230 & $55.6 \%$ \\
\hline
\end{tabular}


Table 4

Perception towards the disease and the vaccine among Adolescent school Girls in Ambo town, Ethiopia, 2021 $(n=414)$

\begin{tabular}{|c|c|c|c|c|c|}
\hline \multirow[t]{2}{*}{ Perceived Susceptibility } & \multicolumn{3}{|c|}{ Poor perception } & \multicolumn{2}{|c|}{ Good perception } \\
\hline & Frequency & Percent & & Frequency & Percent \\
\hline Any women are susceptible to face cervical cancer & 209 & $50.5 \%$ & & 205 & $49.5 \%$ \\
\hline $\begin{array}{l}\text { How much are you worried of contracting HPV } \\
\text { infection }\end{array}$ & 182 & $44 \%$ & & 232 & $56 \%$ \\
\hline $\begin{array}{l}\text { If you don't get vaccinated how likely is it that you'll } \\
\text { become infected }\end{array}$ & 280 & $67.6 \%$ & & 134 & $32.4 \%$ \\
\hline \multicolumn{6}{|l|}{ Perceived Severity } \\
\hline $\begin{array}{l}\text { Being infected with HPV would have major } \\
\text { consequences on life }\end{array}$ & 183 & $44.2 \%$ & & 231 & $55.8 \%$ \\
\hline BeinginfectedwithHPVwouldbe devastating & 149 & $36 \%$ & & 265 & $64 \%$ \\
\hline $\begin{array}{l}\text { It would be very serious if someone became infected } \\
\text { with HPV }\end{array}$ & 167 & $40.3 \%$ & & 247 & $59.7 \%$ \\
\hline \multicolumn{6}{|l|}{ Perceived benefit } \\
\hline $\begin{array}{l}\text { If you get vaccinated you can reduce your risk of } \\
\text { cervical cancer }\end{array}$ & 95 & $23 \%$ & 319 & & $77 \%$ \\
\hline $\begin{array}{l}\text { If you get vaccinated for HPV you can reduce the risk } \\
\text { of vaginal cancer }\end{array}$ & 113 & $27.3 \%$ & 301 & & $72.7 \%$ \\
\hline $\begin{array}{l}\text { Getting vaccinate will decrease your chances of } \\
\text { getting genital warts }\end{array}$ & 208 & $50.2 \%$ & 206 & & $49.8 \%$ \\
\hline \multicolumn{6}{|l|}{ Perceived barriers } \\
\hline Concerns about possible side effects & 277 & $66.9 \%$ & 137 & & $33.1 \%$ \\
\hline Needle phobia & 255 & $61.6 \%$ & 159 & & $38.4 \%$ \\
\hline Miss understanding about HPV vaccine & 237 & $57.2 \%$ & 177 & & $42.8 \%$ \\
\hline Lack of information & 171 & $41.3 \%$ & 243 & & $58.7 \%$ \\
\hline Overall perception & 175 & $42.3 \%$ & 239 & & $57.7 \%$ \\
\hline
\end{tabular}


Table 5

Factors associated with Knowledge of respondents towards HPV vaccination among Adolescent school Girls in Ambo town, Ethiopia, $2021(n=414)$

\begin{tabular}{|c|c|c|c|c|c|c|c|}
\hline \multirow{2}{*}{\multicolumn{2}{|c|}{ Variable }} & & \multicolumn{2}{|c|}{ Level of Knowledge } & \multirow[t]{2}{*}{$\operatorname{COR}(95 \% \mathrm{Cl})$} & \multirow[t]{2}{*}{$\operatorname{AOR}(95 \% \mathrm{Cl})$} & \multirow{2}{*}{$\begin{array}{l}\mathrm{P} \\
\text { Value }\end{array}$} \\
\hline & & & Good & Poor & & & \\
\hline \multirow{2}{*}{\multicolumn{2}{|c|}{ Educational level }} & $\begin{array}{l}\text { Secondary } \\
\text { Education }\end{array}$ & $48(11.6)$ & 102(24.6) & $\begin{array}{l}1.79(1.14 \\
2.82)\end{array}$ & $\begin{array}{l}2.01(1.24 \\
3.26)^{\star}\end{array}$ & 0.005 \\
\hline & & $\begin{array}{l}\text { Primary } \\
\text { Education }\end{array}$ & $55(13.3)$ & $209(50.5)$ & 1.0 & 1.0 & \\
\hline \multirow[t]{6}{*}{$\begin{array}{l}\text { Source of } \\
\text { information }\end{array}$} & \multirow[t]{2}{*}{$\begin{array}{l}\text { Health } \\
\text { providers }\end{array}$} & Yes & $59(14.3)$ & $111(18.8)$ & $2.42(1.54,3.80)$ & $\begin{array}{l}2.13(1.30 \\
3.48)^{\star}\end{array}$ & 0.003 \\
\hline & & No & $44(10.6)$ & $200(48.3)$ & 1.0 & 1.0 & \\
\hline & \multirow[t]{2}{*}{ School } & Yes & $46(11.1)$ & $91(21)$ & $\begin{array}{l}1.95(1.23 \\
3.08)\end{array}$ & $\begin{array}{l}1.66(1.02 \\
2.71)^{\star}\end{array}$ & 0.042 \\
\hline & & No & $57(13.8)$ & $220(53.1)$ & 1.0 & 1.0 & \\
\hline & \multirow[t]{2}{*}{ Internet } & Yes & $11(2.7)$ & $14(3.4)$ & $\begin{array}{l}2.54(1.12, \\
5.78)\end{array}$ & $\begin{array}{l}2.21(0.92, \\
5.31)\end{array}$ & 0.076 \\
\hline & & No & $92(22.2)$ & 297(71.7) & 1.0 & 1.0 & \\
\hline
\end{tabular}


Table 6

Factors associated with Attitude of respondents towards HPV vaccination among Adolescent school Girls in Ambo town, Ethiopia, $2021(n=414)$

\begin{tabular}{|c|c|c|c|c|c|c|}
\hline \multirow[t]{2}{*}{ Variable } & & \multicolumn{2}{|c|}{$\begin{array}{l}\text { Attitude of the } \\
\text { respondents }\end{array}$} & \multirow[t]{2}{*}{$\operatorname{COR}(95 \% \mathrm{Cl})$} & \multirow[t]{2}{*}{ AOR(95\%Cl) } & \multirow{2}{*}{$\begin{array}{l}\mathrm{P} \\
\text { Value }\end{array}$} \\
\hline & & Favorable & Unfavorable & & & \\
\hline \multirow[t]{2}{*}{$\begin{array}{l}\text { Ever heard about HPV } \\
\text { vaccine }\end{array}$} & Yes & 273(65.9) & $53(22.8)$ & $\begin{array}{l}8.15(4.64 \\
14.4)\end{array}$ & $\begin{array}{l}3.43(1.341 \\
8.74)^{\star}\end{array}$ & 0.01 \\
\hline & No & $32(7.7)$ & $56(13.5)$ & 1.0 & 1.0 & \\
\hline \multirow[t]{2}{*}{ Perceived Susceptibility } & Good & 167(40.3) & $32(7.7)$ & $\begin{array}{l}2.16(1.45 \\
3.22)\end{array}$ & $\begin{array}{l}1.07(0.6 \\
1.9)\end{array}$ & 0.826 \\
\hline & Poor & 138(33.3) & 77(18.6) & 1.0 & 1.0 & \\
\hline \multirow[t]{2}{*}{ Perceived Severity } & Good & 215(51.9) & $31(7.5)$ & $\begin{array}{l}4.19(2.76, \\
6.36)\end{array}$ & $\begin{array}{l}2.89(1.61 \\
5.21)^{\star}\end{array}$ & $<0.001$ \\
\hline & Poor & $90(21.7)$ & $78(18.8)$ & 1.0 & 1.0 & \\
\hline \multirow[t]{2}{*}{ Perceived Barrier } & Good & $101(24.4)$ & $116(28)$ & $\begin{array}{l}0.46(0.31,0 \\
.68)\end{array}$ & $\begin{array}{l}0.5(0.3 \\
0.84)^{\star}\end{array}$ & 0.009 \\
\hline & Poor & 129(31.2) & $68(16.4)$ & 1.0 & 1.0 & \\
\hline \multirow[t]{2}{*}{$\begin{array}{l}\text { Availability of } \\
\text { awareness creation }\end{array}$} & Yes & 173(41.7) & $28(6.7)$ & $3.28(2.17,4.94)$ & $\begin{array}{l}\text { 1.93(1.06, } \\
3.51)^{\star}\end{array}$ & 0.032 \\
\hline & No & 132(31.8) & 81(19.5) & 1.0 & 1.0 & \\
\hline
\end{tabular}

